R. Italianistlca, São Paulo, ano II, n² 2, p. 53-59, 1994.

\title{
A ENGENHARIA LITERÁRIA E A ÁRVORE DA VIDA. O Pêndulo de Foucault de U. Eco
}

\author{
Vilıma de Katinszky Barreto de Souza*
}

Resumo: A Itília pớs-moderna na visão dn crítica plástica. Achille Bonito Oliva e a pintura dos três Cs; a literatura e a reconstrução do Universo na engenharia literária do Pêndulo de Foucault. A interpretação ficcional do escritor italiano alravés da tradiçño cabalistica hebraica da Árvore da Vida ou a Árvore de Jessé e a Árvore Sefirótica.

Palavras-chave: Itália pós-modernn, ficção e tradiçño, árvores do universo.

Antes de abordarmos a obra de Eco como uma das manifestaçōes da Itália pós-moderna ou a "transvanguarda" na literatura italiana veremos que, mais diretamente, a crítica da Península se manifesta nas artes visuais, especialmente no discurso das imagens pictóricas. Achille Bonito Oliva considera que, à queda da vanguarda, seguiu-se o declínio da Arte Conceitual, sobre a qual trabalhou no início de sua carreira. Chamou de transvanguarda ao trabalho dos três Cs: Clemente, Chia e Cucchi, bem como o de Mimmo Paladino e Nicola De Maria, estabelecendo como premissa o colapso da legitimidade que afirmou estar por trás da vanguarda modernista e a que chamou de "darwinismo lingüístico". Constatou uma arte que usa ecleticamente um material de períodos históricos diferentes e de diversos locais geográficos, relacionados com a identidade de outros tempos e lugares regionais. Contra uma noção de história da arte em desevolvimento linear, baseado numa visāo histórica iluminística como progresso, assim nos dá um modelo de descontinuidade: "O preceito inicial é o da arte como a produção de uma

* Professora de Literatura Italiana junto ao Deparlamento de Letras Modernas da Faculdade de Filosofia, Letras e Ciências Humanas, USP. 
SOUZA, Vilma de Katinszky Barrelo de. A engenharia literária e a árvore da vida. O péndulo de Foucault de U. Eco.

catástrofe, uma descontinuidade que destroi o balanço teutônico da linguagem em favor de uma precipitação no sujeito do "imaginário", não um nostálgico retorno ou um refluxo mas um fluxo que carrega dentro de si a sedimentação de muitas coisas que ultrapassam uma simples volta ao particular e ao simbólico" Bonito Oliva afirma a catástrofe como uma "quebra das necessidades sociais" em que a arte afirma o seu próprio valor pela sua irredutibilidade", a irredutibilidade dos seus fragmentos e a impossibilidade de recriar a unidade e o equilíbrio: ao invés do trabalho como um fragmento implicado na totalidade dentro das ideologias políticas, psicanalíticas e científicas, o trabalho se realiza "transferindo seus fins de fora para dentro, na possibilidade que tem de estabelecer o fragmento como uma totalidade, que só relembra um valor fora do fato de sua própria aparência" Esses desvios do perfil da vanguarda de "colocar-se como um questionamento" apresentou uma imagem que é "simultaneamente enigma e solução" $O$ conceito de subjetividade que subjaz é o de fragmentação. "Essa subjetividade está declarada na sua verdadeira fragmentação e fluidez. O movimento característico dessa subjetividade é o "fluxo": "a linguagem não segue mais a lógica ou a corrente principal dos anos recentes, caracterizada pelo desenvolvimento linear e consistente. Uma nova expressividade finca suas raízes num nomadismo aberto e impulsivo, sem se deixar enredar num desenvolvimento geométrico e conseqüente. A idéia que propulsiona esse novo trabalho é a de fluxo: um movimento sem direções preconstituídas, sem partida nem chegada mas acompanhado do desejo de encontrar um ancoradouro provisório nos contornos, em movimentos de sensibilidade" Esses artistas são nômades, "encontrando na leveza do nomadismo a possibilidade de uma imagem na encruzilhada da repetiçāo e da diferença" Enquanto a arte pós-conceitual toma como referência Lacan, Althusser, Foucault e o último Derrida, a fim de formular uma crítica ao sujeito burguês, A. B. Oliva adapta aos seus fins a "produção desejosa" de Deleuze e o livro de Guattari Anti-Oedipus (1972) em que eles opõem um "desejo" fluido e amorfo às agências repressivas da lei e das instituições (em vez de ver o desejo e a lei mutuamente dependentes, como para Lacan) ${ }^{1}$

1 Cf. Michael Newman, Revising Modernism, represenling PosImodernism. Todas as expressões entre aspas representam conceitos tiraclos da obra de A. B. Oliva elencada no fim do trabalho. 
Para entrar na atmosfera pós-moderna da Itália precisamos conhecer alguma coisa da "engenharia" de três escritores considerados pós-modernos que se ligam pela expressão "engenharia literária" emprestada de um crítico italiano, Ferretti, referido por C. Benussi, em seu livro Il Punto su Moravia ${ }^{2}$, que também a utiliza como denominador comum a A. Moravia, I. Calvino e U. Eco. Saltemos os dois primeiros com a sua obra monumental, lembrando apenas que Moravia, incansável viajante, quer escrever um livro "inexistente" em quatro capítulos, com os seus relatos de viagem ao terceiro mundo onde encontra na África o baobá, um colosso vegetal que tem "uma utilidade - como dizer - espiritual: é considerado a sede perfeita de espíritos, espectros e fantasmas" ${ }^{3}$ Do mesmo modo que Moravia, seduzido por esse protagonista mágico, Italo Calvino, num tempo aproximado, num outro lugar, agora na América encontrou "a árvore de Tule" "que se diz ter dois mil anos de idade... "aproximando-me antes ainda de que o olho percebesse é como se uma sensação ameaçadora me tomasse: como se daquela nuvem ou montanha vegelal... viesse a advertência de que a natureza, a passos lentos, pretende desenvolver um plano que nada tem a ver com as proporçōes humanas" 4 Gostaríamos de indicar essas duas visōes do mistério vegetal para ver nele o reflexo antropológico que o talento e a arte de Moravia e a de Calvino nos permitem: de um lado o reinado inconteste de um mundo incontaminado e inocente; de outro a identidade antropomórfica que remonta à gênese da humanidade: aqui a origem e explicação da "árvore genealógica" cuja forma seria reconstruída, remontando às raízes do gênero humano. Esse mesmo fio passa pela Árvore de Jessé da iconografia cristã e envolve a grande árvore sefirólica de Cesare Evola, um veneziano do século VI, que Umberto Eco planta em seu último livro I/ Pendolo di Foucault e da qual desenvolve o plano de toda a obra. Ao analisarmos a estrutura do livro verificamos que os dez capítulos correspondem aos dez ramos da Árvore de Sefirot, ou seja, dos nomes com que os hebreus indicavam os tributos divinos. $O$ romance é o desenvolvimento e a tentativa de explicação da vida terrestre desde a sua origem através das etapas do desvendamento do grande mistério vital até o futuro remoto, que já coexiste com o presente e está, principalmente, no passado mais remoto. $O$ péndulo que inicia e enfecha a obra, perpassa através dela o seu movimento, que representa a rotação e o período da existência terrestre e humana. Oscilando entre os dois pontos do extremo oriente e

2 V. bibliografia.

3 Passeggiate africane (tracluçño nussa dos textos citados), v. bibliografia.

4 Collezione di sabbia (traduçño nussa lus textus citadus), v. bibliografia. 
SOUZA, Vilma de Katinszky Barreto de. A engenharia literária e a árvore da vida. O pêndulo de Foucault de U. Eco.

ocidente, desenvolve uma trajétoria não linear mas contínua de todos os pontos da geometria euclidiana e einsteniana, na sua simplicidade e correspondência complexiva. O tempo também não é linear: todos os seres coexistem, imergem no desconhecido mas voltam continuamente, a cada geração, incarnando naqueles que sempre tiveram a preocupação de desvendar os mistérios da nossa existência. O pêndulo é o movimento que carrega a vida e a morte e faz sua vítima uma das três personagens, Stefano Belbo, que é encarregado de executar um projeto ou um plano para um futuro livro. Além de Belbo encontramos como personagens da atualidade no romance Casaubon, escritor-narrador, intelectual, que tem o mesmo nome de um filólogo do Renascimento, e Diotallevi, chamado do mesmo modo que um velho professor de hebraico e que constitui a ponte entre os conhecimentos modernos e a sabedoria do mundo oriental e antigo, contida nos livros sagrados e na Torah. O desenvolvimento do livro é a explicação do sentido de cada ramo sefirótico da grande árvore: é ela que explica a grande comédia de erros em que estamos todos envolvidos: o universo e a humanidade. Com a ironia e com a linguagem absolutamente sarcástica com que Eco se revela e se expressa vai identificando a confusão, a identidade dos opostos e contrários, a ocultação do sentido e a ilegibilidade das palavras (lembremo-nos do Cosmicomiche de Calvino...). Assim, a primeira sefirah ou ramo da árvore é Keter, a Coroa, a origem, o vazio primordial. Keter ou o pensamento desenhou todas as figuras: era e não era, fechado no nome e fugido do nome só tinha o nome Quem? puro desejo de ser chamado por um nome. Do centro, uma fonte de chamas passou a iluminar os sefiroth inferiores até ao último, o Reino. Talvez neste tsimtsum, neste retiro, nesta solidão, já existisse a promessa do tiqqum, a promessa da volta. E por aí vai se espalhando essa árvore sagrada e grotesca que abarca o mundo e, ao memo tempo o desintegra na sua incompreensão profunda. No segundo ramo, o Hockmah vemos abrigada a ciência da combinação das letras e a da purificação dos corações. Lógica mística, o mundo das letras e do seu redemoinho de permutações infinitas é o mundo da beatitude, música do pensamento que pode levar ao éxtase mas também ao delírio se a sua manipulaçāo exagerada ou errada nāo levar ao domínio da natureza. Mas a máquina moderna Abulafia, que é como Belbo chama o Computador, onde ele deve organizar os programas de tom verdadeiramente cabalísticos, comparada ao produto da Santa Cabala e da Tradição fecharia o ciclo do Universo se o seu resultado não permanecesse em segredo: de outro modo "nós refulgiremos imêmores na glória do grande Melátron"(p. 42) 
(A ARVORE DE JESSE)

(A ARVORE DA VIDA)

ARVORE SEFIROTICA

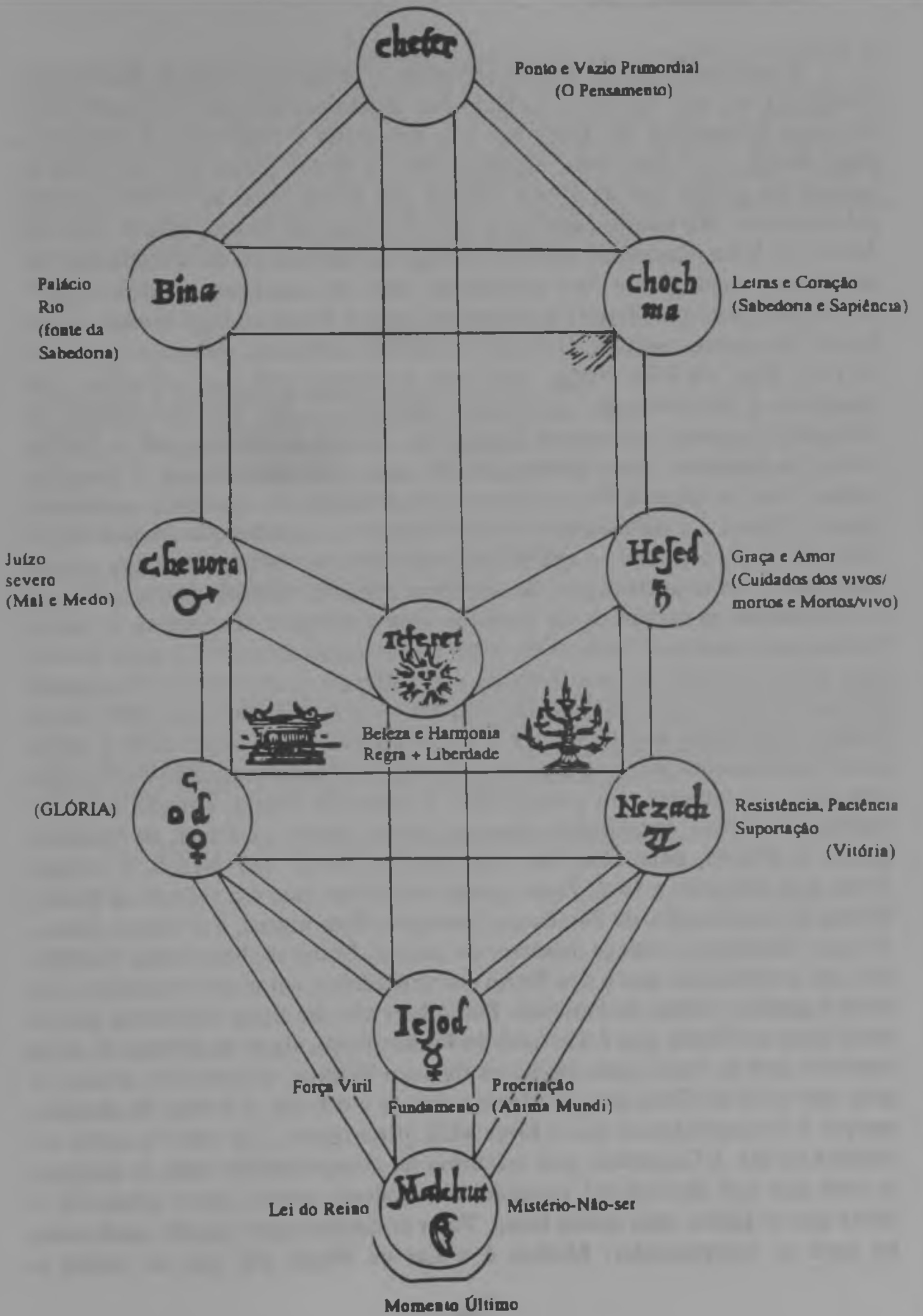

Momen Uo Ultimo 
SOUZA, Vilma de Katinszky Barreto de. A engenharia literária e a árvore da vida. $O$ pêndulo de Foucault de U. Eco.

O terceiro ramo da árvore sefirótica é Binah ou o que o discurso de Diotallevi destaca: Binah é o palácio que Hockmah constrói, expandindo-se do ponto primordial. Se Hockmah é a Sabedoria e Sapiência, é também a fonte Binah, o rio que brola, dividindo-se em vários ramos até que todos se joguem no grande mar da última sefirah. Em Binah todas as formas já estão pré-formadas. No quarto capítulo a que ele chama de Hesed, quarto ramo da Árvore da Vida, Casaubon deixa-se imergir no sentimento da semelhança das misteriosas analogias e "no crepúsculo onde se anulavam as diferenças" Dizia Diotallevi que Hesed é a sefirah da graça e do amor, fogo branco, vento do sul. No quinto capítulo, Geburah, da árvore sefirótica, relorna o problema do Pólo Fixo ou Pólo Nada, onde está o Pêndulo em que o homem ateu interpreta a fé dentro da sua cultura ocidental. À luz do Juízo severo de Geburah, chamado também de Pachad ou Terror, a sefirah onde o Mal se exibe, as conchas ou os princípios da ruína que aguardavam à espreita, tomam uma existência real. Se Geburah é a séfirah do mal e do medo (ver figura) Tiferet é a da beleza e da harmonia, é a especulação iluminante, o cerne da vida, o prazer, a aparência purpurina e o acordo da Regra com a Libedade. Para as personagens do romance, segundo Casaubon, o ano em que se celebraram os esponsais da Tradição com a Máquina Eletrônica, o tempo em que inventaram o Plano, bem como a concepção de um filho para Casaubon, para o término do livro Tratado sobre Metais, para o senhor Garamond publicar uma história ilustrada das ciências mágicas e herméticas, para Belbo conseguir dominar absolutamente o seu computador, inserindo nele o máximo de informações sobre a reescrita do Livro do Mundo (segundo o seu plano tudo isso, certamente, foi atingir Hod, o ramo da Glória, situado na parte inferior da árvore, constituído como os demais ramos até Jesod, de "matéria grossa"). Porém, para atingi-lo seria preciso passar por Nezah, o sétimo ramo, que antecede a Hod. Para alguns intérpretes esta $\varepsilon$ a sefirah da Resistência, da suportação, da Paciência constante. Para outros, é a vitória, mas... do quê? Diotallevi começa a morrer de câncer, Belbo roubado pelos diabólicos que acreditaram que o seu Plano era verdadeiro, cai numa armadilha e se torna a grande vítima do Pêndulo. Diotallevi não lhe tinha explicado que se pode estar em Jesod, que é a sefirah do Fundamento, signo da aliança do arco superior, que se estica para enviar as flexas a Malkul, último alvo. Jesod gota que salta da flexa para produzir a árvore e o fruto, é a alma do mundo, porque é o momento em que a força viril, procriando, liga entre si todos os estados do ser. E Casaubon, que acreditou ter compreendido tudo, se pergunta pela paz que deveria ter atingido; a sabedoria maior, nesse momento é saber que se soube tudo muito tarde. Tudo se compreende quando nada mais há para se compreender: Malkul é a Lei de Reino em que se exilou a 
R. Italianística, São Paulo, ano II, n² 2, p. 53-59, 1994.

Sabedoria, tateando para reencontrar a própria lucidez perdida. A verdade de Malkut, a única verdade que brilha na noite das sefirot é que a sabedoria que se descobre nua em Malkut é que o próprio mistério está no não-ser, no último momento. Depois recomeçam os outros e com eles os diabólicos, a procurar abismos onde se esconda o segredo que é a sua loucura. Todos se perdem ao perder a Ocasiāo mas a última personagem se consola com a idéia de que com a morte ela também se esquecerá de tudo.

\section{BIBLIOGRAFIA}

CALVINO, I. Collezione di sabbia. Milano, Garzanti, 1984.

MORAVIA, A. Passeggiate africane. Milano, Bompiani, 1987.

ECO, U., II Pendolo di Foucrult. Milano, Bompiani, 1988.

RUSSEL, C. The context of the concept. Newark, 1988-89. vol I.

BENUSSI, C. Il punto su Mormvia. Roma - Bari, Laterza, 1987.

OLIVA, A. Bonito. Il tallone di Achille. Milano, Feltrinelli, 1988. . Il sogno dell'arte. Milano, Spirale/Vel, 1990. Antipatia. Milano, Feltrinelli, 1987.

Abstract: Pust-modern Italy in the vision of the plastic criticism. Achille Bonito Oliva and the three Cs painters; literature and the reconstruction of Universe in the literary enginery of Umberto Eco's Pendulum of Foucault. The fictional interpretation of the Italian writer through hebraic caballistic tradition from the Tree of life or the Jessé's Tree and the Sefirotic Tree.

Key-word: Italy, pust-modernism, fiction and tradition, universe trees. 